\title{
MONITORAMENTO DO CICLO ESTRAL DE FÊMEAS EQUINAS POR MEIO DE CITOLOGIA VAGINAL, ULTRASSONOGRAFIA E DOSAGEM HORMONAL
}

\author{
Muriel Magda Lustosa Pimentel ${ }^{1}$ \\ Fernanda Araujo dos Santos ${ }^{1}$ \\ Regina Valéria da Cunha Dias ${ }^{1}$ \\ Luã Barbalho de Macêdo² \\ Zuliete Aliona Araújo de Souza Fonseca ${ }^{1}$ \\ Weibson Paz Pinheiro André 2 \\ Wesley Lyeverton Correia Ribeiro ${ }^{4}$
}

PIMENTEL, M. M. L.; SANTOS, F. A. dos; DIAS, R. V. C.; MACÊDO, L. B. de; FONSECA, Z. A. A. de S.; ANDRÉ, W. P. P.; RIBEIRO, W. L. C. Monitoramento do ciclo estral de fêmeas equinas por meio de citologia vaginal, ultrassonografia e dosagem hormonal. Arq. Ciênc. Vet.Zool. UNIPAR, Umuarama, v. 17, n. 1, p. 69-75, jan./mar. 2014.

RESUMO: O ciclo estral é a sincronia entre eventos comportamentais, anatômicos e endócrinos que resultam na ovulação, e pode ser dividido em fase lútea e fase folicular. A identificação das fases do ciclo estral da égua pode ser acompanhada por meio de várias biotécnicas reprodutivas como, por exemplo, citologia vaginal classificando os diversos tipos de células do epitélio vaginal, ultrassonografia para avaliação da dinâmica folicular e a dosagem hormonal no plasma sanguíneo ou das fezes do animal para caracterizar a fase do ciclo estral que o animal possivelmente se encontra. Sendo assim, o objetivo desta revisão foi discutir a fisiologia do ciclo estral de éguas, a fim de favorecer novas pesquisas relacionadas à biotécnicas reprodutivas para equinos.

PALAVRAS-CHAVE: Biotecnologia da reprodução. Éguas. Monitoramento.

\section{MONITORING EQUINE ESTROUS CYCLE THROUGH VAGINAL CYTOLOGY, ULTRASONOGRAPHY AND HORMONE DOSAGE}

\begin{abstract}
The estrous cycle is the synchrony of behavioral, anatomical and endocrine events that result in ovulation. It can be divided into luteal and follicular phases. The identification of the stages in the estrous cycle of mares can be accomplished through several reproductive biotechnologies, such as, for instance, vaginal cytology classifying the different types of cells in the vaginal epithelium, follicular dynamics evaluated through ultrasound examination, and hormone dosage in blood plasma or feces from the animal to characterize the likely estrous cycle phase. Thus, the objective of this review is to discuss the physiology of the estrous cycle in mares in order to encourage new research related to reproductive biotechnologies for horses.
\end{abstract}

KEYWORDS: Reproduction biotechnology. Mares. Monitoring.

\section{MONITOREO DEL CICLO ESTRAL DE HEMBRAS EQUINAS POR MEDIO DE CITOLOGÍA VAGINAL, ULTRASONIDO Y DOSIS HORMONAL}

RESUMEN: El ciclo estral es la sincronía entre eventos de comportamiento, anatómicos y endocrinos que resultan en la ovulación, y se puede dividir en fase lútea y fase folicular. La identificación de las etapas del ciclo estral de la yegua puede ser acompañada a través de varias biotécnicas reproductivas como, por ejemplo, citología vaginal, clasificando los diferentes tipos de células del epitelio vaginal, ultrasonido para evaluación de la dinámica folicular y la dosificación hormonal en el plasma sanguíneo o de las heces del animal para caracterizar la fase del ciclo estral que el animal posiblemente se encuentra. Así, el objetivo de esta revisión ha sido examinar la fisiología del ciclo estral de yeguas, con el fin de fomentar nuevas investigaciones relacionadas con las biotecnologías reproductivas para equinos.

PALABRAS CLAVE: Biotecnología de la reproducción. Yeguas. Monitoreo.

\section{Introdução}

Devido a fatores sazonais e evolutivos, a estação reprodutiva fisiológica na maioria das éguas inicia após um anestro de inverno, com uma fase transicional de ressurgência, para então apresentar comportamento de estro acom- panhado de ovulação periodicamente, a partir do final da primavera até o fim do verão (DAVID, 2010). A alta variabilidade na duração do período do estro e a dificuldade em prognosticar o momento exato da ovulação, levaram ao desenvolvimento de métodos para controle do ciclo estral e da ovulação, especialmente para aumentar o desempenho repro- 
dutivo tanto de garanhões como de éguas durante a estação de monta (MELO et al., 2012).

Os sinais de estro são induzidos pela elevada concentração de estradiol na circulação, proveniente do folículo dominante, que secreta mais de $80 \%$ dessa substância e pelos níveis decrescentes de progesterona, nesse estágio. $\mathrm{O}$ corpo lúteo $(\mathrm{CL})$ é o local de produção da progesterona (P4), que promove o encerramento dos sintomas de estro, mantém a fêmea não receptiva ao macho e prepara o útero para a recepção do embrião. Diferentes níveis plasmáticos de P4 durante o ciclo estral têm sido reportados, considerando durante o estro, níveis inferiores a $1 \mathrm{ng} / \mathrm{ml}$. Apesar da importância da existência e funcionalidade do CL durante o ciclo estral e gestação, a presença e o estágio da glândula luteínica não podem ser avaliados com precisão por meio de palpação retal. As dosagens de P4 e estrógeno são mais eficientes para indicar a atividade da glândula luteínica e do folículo dominante, respectivamente (TAROUCO, 2013).

A citologia vaginal esfoliativa é uma técnica fácil e de baixo custo (GUIMARÃES, et al. 2008), que consiste na monitoração das diversas fases do ciclo estral (SNOECK et al., 2011). Por ser constituído por camadas morfologicamente distintas, o epitélio vaginal em diferentes espécies, a exemplos de Agouti paca, é alterado de acordo com o estímulo hormonal predominante em cada fase, as quais podem ser identificadas mediante métodos apropriados de coloração histológica, consistindo na observação de diferentes células do epitélio vaginal (RIBEIRO et al., 2012). A técnica é usada em associação à observação dos sinais clínicos, para determinação das fases do ciclo estral (BENETTI et al., 2004).

A ultrassonografia (US) tem sido amplamente utilizada como auxílio para a avaliação das funções reprodutivas, assim como no diagnóstico de patologias. O desenvolvimento da técnica permitiu a adaptação para diferentes animais domésticos. Em curto espaço de tempo, a imagem obtida por meio US tem contribuído para o conhecimento de diversos fenômenos da fisiologia reprodutiva, uma vez que pode ser realizada por vários dias, de forma alternada ou em observação contínua de um evento dinâmico, permitindo desta maneira a obtenção de importantes informações morfológicas sem invadir ou causar dano aos tecidos (PEIXOTO, 2010).

Fotoperiodismo é a habilidade de acessar e usar a quantidade de informação luminosa percebida durante o dia como dado antecipatório aos eventos sazonais do ambiente (BRADSHAW; HOLZAPFEL, 2007). A duração do dia, em horas de luz, constitui um calendário utilizado por várias espécies em preparação à próxima estação.

Sendo assim, o objetivo desta revisão é discutir a fisiologia do ciclo estral de éguas, abordando características hormonais, aspectos da citologia vaginal e ultrassonográficas, a fim de favorecer maiores pesquisas dessas biotécnicas relacionadas a equinos.

\section{Ciclo reprodutivo na égua}

A égua é um animal poliéstrico estacional, com duração do ciclo estral de 20 a 21 dias, apresentando mais de um ciclo estral dentro de um período específico. Sua atividade reprodutiva é regulada, principalmente, pela quantidade de luz (fotoperíodo), mas também por fatores nutricionais e climáticos (SAMPER, 2008).
O ciclo estral é definido como a sequência de alterações anatômicos e endócrinos que preparam a fêmea para a ovulação (SAMPER, 2008; FERREIRA, 2009). Na égua, o ciclo estral pode ser dividido em estro (fase folicular) e diestro (fase luteal). A fase folicular dura em média sete dias e a fase luteal em média 15 dias. Durante o estro a égua é sexualmente receptiva ao garanhão. Neste período, o folículo dominante se desenvolve e secreta estrógeno, que induz o comportamento de estro. A ovulação geralmente ocorre 24 a 48 horas antes do final da receptividade sexual (LAGE, 2007; PORTO, 2007).

O proestro é o período em que ocorre a maturação de um ou mais folículos, sob a influência do FSH. O folículo começa a secretar estrógeno, que influencia os órgãos genitais. Os níveis crescentes de estrógenos suprimem níveis de progesterona em declínio. Essa fase de maturação folicular na égua, dura de dois a seis dias. A atividade ovariana e o crescimento folicular ocorrem em resposta ao aumento da duração da luz do dia (GOMES, 2003).

O estro é o momento em que ocorre a ovulação e no qual a égua está receptiva sexualmente. Os folículos secretam grande quantidade de estrógenos $\left(\mathrm{E}_{2}\right)$, responsáveis pelo surgimento do cio, essa elevada secreção de estrógenos pelos folículos pré-ovulatórios, é responsável pela estimulação do crescimento uterino, através da interação do hormônio $\left(\mathrm{E}_{2}\right)$ com receptores e aumento de processos sintéticos celulares. Nas éguas, o cio tem duração de cinco a sete dias, a ovulação se dá geralmente no terço final do cio (SAMPER, 2008). Este período é marcado pela receptividade sexual bem característica, mas em algumas éguas, só é perceptível por acompanhamento folicular, através de exame ultrassonográfico, uma vez que as manifestações psíquicas não são demonstradas (cio silencioso). Essa manifestação é muito comum no período conhecido como "cio do potro", que ocorre entre $5^{\circ}$ e $15^{\circ}$ dia pós parto (ROMANO, 1998).

O metaestro é um estágio de transição no qual o estrógeno em declínio é contrabalanceado pela $\mathrm{P}_{4}$ em elevação. Após a ovulação ocorre formação de corpo lúteo, que se desenvolve em três ou quatro dias formando uma glândula hormonal. No caso de fecundação e desenvolvimento do embrião, o corpo lúteo é mantido por período mais longo. Quando não ocorre a fecundação, ele atrofia (LAGE, 2007).

$\mathrm{O}$ diestro é o período de secreção da $\mathrm{P}_{4}$ pelo corpo lúteo, a fertilização dos ovócitos e a subsequente gestação resultam no prolongamento do diestro. A duração do diestro varia entre as espécies, nos equinos dura, em média, cinco a seis dias (SAMPER, 2008).

O início do anestro pode ocorrer por três formas distintas: 1- após um prolongamento espontâneo do corpo lúteo; 2- após a luteólise de um corpo lúteo regular; 3- após atresia folicular. $\mathrm{O}$ anestro verdadeiro é o período de inatividade ovariana sem ovulação, com baixos níveis séricos de $\mathrm{P}_{4}$, perda do tônus uterino e atrofia gonadal. Ocorre como resultado de uma redução na concentração de GnRH e LH no hipotálamo e na pituitária anterior, respectivamente. A ausência de atividade reprodutiva durante o anestro é causada provavelmente pela supressão da secreção de GnRH induzida por uma série de sistemas neuronais inibitórios que fazem a transmissão de fatores externos e internos como fotoperíodo, nutrição, temperatura e ritmo endógeno circanual (BISOL, 2007). 


\section{Influência hormonal}

O controle endócrino do ciclo estral deve-se ao eixo hipotalâmico-hipofisário-gonadal, que é controlado principalmente pelo fotoperíodo, além da influência nutricional, temperatura, ambiente, condição corporal, idade e raça do animal. A duração do período de luminosidade dos dias influencia inversamente a produção de melatonina, que controla a atividade do eixo hipotalâmico - hipofisário - gonadal. A melatonina tem efeito inibidor na produção do hormônio libertador de gonadotrofina ( $\mathrm{GnRH})$, estimulante da produção de dois hormônios que atuam nos ovários - hormônio luteinizante (LH) e hormônio folículo-estimulante (FSH) (FERREIRA, 2009).

O hormônio FSH e o LH, produzidos na hipófise anterior, são hormônios glicoproteicos, o primeiro possui a função de promover o crescimento dos folículos e controlar a síntese de estrógenos, atuando na granulosa. Já o segundo, participa da síntese de estrogênios, possui como função primária estimulação, maturação e evolução do folículo antral e secundariamente, formação e manutenção do CL (FERREIRA, 2009).

O FSH é responsável pelo desenvolvimento dos folículos ovarianos. A sua liberação é bifásica, apresentando níveis mais elevados nos dias nove a 12 e próximo da ovulação. O pico próximo da ovulação ocorre dois dias antes desta, quando o estradiol produzido pelo folículo dominante diminui, o que permite completar o desenvolvimento final do folículo pré-ovulatório e iniciar o desenvolvimento de novos folículos. O declínio dos níveis de FSH ocorre com o aumento do hormônio inibina, produzido pelos folículos maiores que $13 \mathrm{~mm}$ (GINTHER et al. 2008).

Os principais hormônios esteróides são progestágenos e estrógenos. $\mathrm{A}_{4}$ é produzida pelo $\mathrm{CL}$, placenta e córtex adrenal e sua secreção é controlada pelo LH no animal não prenhe, promovendo crescimento de glândulas endometriais do útero estimulando a atividade secretora do oviduto, evitando a contratação uterina durante a gestação e por fim, regulando a secreção de gonadotrofinas. Os estrógenos por sua vez, possuem como local de produção o ovário, unidade feto placentária e o córtex adrenal, sendo representados pelo estradiol-17 $\beta$, estriol e estrona (IZAEL, 2007).

No estro, a concentração de LH aumenta até atingir o pico dois dias depois da ovulação. Como resultado da ovulação, forma-se o CL produtor de $\mathrm{P} 4$ e que tem efeito inibitório na libertação de LH. Os níveis de $\mathrm{P}_{4}$ aumentam em 24 - 48 horas no período pós ovulação e mantêm-se durante 14 - 15 dias do ciclo éstrico. Se a égua não estiver gestante, por volta do $15^{\circ}-16^{\circ}$ dia ocorre diminuição da concentração de $\mathrm{P}_{4}$, permanecendo em níveis basais durante o estro. Esse declínio deve-se à secreção de PGF2 $\alpha$ a partir do endométrio entre os dias 13 e 16 pós-ovulação, que induz a regressão do CL. A secreção de PGF2 $\alpha$ precede a diminuição da concentração plasmática de $\mathrm{P}_{4}$ em três ou quatro horas (FERREIRA, 2009).

A ocitocina é sintetizada no núcleo supraóptico do hipotálamo e transportada em pequenas vesículas envoltas por uma membrana por meio dos axônios do nervo hipotálamo-hipofisário. Elas são armazenadas nos terminais nervosos próximos dos leitos capilares na neuro-hipófise até a sua liberação para a corrente circulatória. A ocitocina é também produzida pelo corpo lúteo. Portanto, a ocitocina tem dois sítios de origem: um ovariano e outro hipotalâmico. A ocitocina desempenha papel no processo reprodutivo. Durante a fase folicular do ciclo estral e durante os últimos estágios da gestação, a ocitocina estimula as contrações uterinas, que facilitam o transporte do esperma para o oviduto durante o cio. Além disso, a ocitocina ovariana está envolvida na função luteínica. Ela age no endométrio induzindo a liberação de $\mathrm{PGF}_{2} \alpha$, que possui uma ação luteolítica (regressão do corpo lúteo) (HAFEZ; HAFEZ, 2004).

Pelo fato da progesterona atingir níveis basais durante o estro, o seu efeito inibitório sobre a secreção de gonadotrofinas deixa de ocorrer, e assim é iniciado todo o processo hormonal responsável pelo estro e ovulação. De modo geral, as éguas se encontram em cio por volta do dia 15-16 do ciclo estral, quando a $\mathrm{PGF}_{2 \alpha}$ é produzida pelo endométrio e induz a luteólise. Aproximadamente no $5^{\circ}$ dia de cio ocorre a ovulação, que resulta na formação de corpo lúteo, que só responde à $\mathrm{PGF}_{2 \alpha}$ exógena quando está maduro, em média cinco dias depois da ovulação (FERREIRA, 2009).

$\mathrm{O}$ estradiol é produzido pelo folículo dominante, atingindo seu pico cerca de dois dias antes da ovulação, logo depois começa a diminuir. A concentração sanguínea de LH aumenta lentamente no início da ovulação, evidenciando-se um rápido acréscimo da sua concentração simultâneo ao pico de estradiol, com pico de LH um dia após a ovulação. A diminuição do estradiol no final do crescimento do folículo pré-ovulatório, cerca de dois dias antes da ovulação deve-se ao estabelecimento de um efeito negativo recíproco de LH na produção folicular de estradiol, a partir do momento em que a concentração de LH atinge um limiar crítico. A diminuição inicialmente rápida nas concentrações de estradiol observada um a dois dias antes da ovulação é consequência do efeito negativo que o rápido aumento de $\mathrm{LH}$ exerce sobre o estradiol, enquanto que a diminuição lenta de estradiol observada um dia após a ovulação é atribuída ao menor efeito negativo exercido pela $\mathrm{LH}$, cujos níveis diminuem lentamente nesta fase (GINTHER et al. 2008).

Estudos realizados por Donadeu e Watson (2007), comprovam a existência de uma relação temporal direta entre o aumento da circulação de LH, mas não de FSH, e o desenvolvimento de ondas foliculares maiores, concluindo-se neste trabalho citado, que as concentrações de LH acima das necessárias ao crescimento do folículo dominante são importantes para a aquisição da competência para ovular, isto é, para que o folículo dominante se torne totalmente responsivo ao aumento de LH (DONADEU e PEDERSEN, 2008). Na égua, tem sido referida a existência de um número elevado de receptores de LH nos folículos dominantes, em contraste com o observado em folículos menores (GOUDET et al., 1999). Estudos indicam que o fluído folicular rico em hormônios passa através das fímbrias do oviduto para a cavidade peritoneal durante a ovulação, sendo estas depois absorvidas a partir do peritoneo, o que estará na origem das alterações das concentrações circulantes de estradiol e inibina, que por sua vez interferem nas concentrações de LH e FSH (GINTHER et al., 2008).

Ginther et al. (2008) constataram a ocorrência de um ligeiro aumento na concentração de progesterona no dia da ovulação. O decréscimo nas concentrações circulantes de LH observado no dia seguinte ao da ovulação está relaciona- 
do com o efeito negativo exercido pelo aumento pós-ovulatório de progesterona (GINTHER et al., 2008). A concentração plasmática de progesterona aumenta rapidamente após a ovulação, mantendo-se elevada por 14-15 dias na égua não gestante (BOTELHO, 2012) e atingindo um valor máximo, superior a $4 \mathrm{ng} / \mathrm{ml}$, aos quatro a sete dias após a ovulação (EVANS et al., 1997), e de quatro a cinco dias antes da próxima ovulação os níveis de progesterona vão diminuindo. $\mathrm{Na}$ ausência de gestação, no final do diestro, por volta de 14-15 dias após a ovulação, observa-se a produção de PGF $_{2 \alpha}$ pelo endométrio (EVANS et al., 1997), que induz a luteólise e, consequentemente, a diminuição dos níveis plasmáticos de progesterona, que retornam a valores inferiores a $1 \mathrm{ng} / \mathrm{ml}$ (BOTELHO, 2012). Na égua, ao contrário do que está descrito em vacas e ovelhas, a $\mathrm{PGF}_{2 \alpha}$ produzida pelo endométrio é absorvida pelo sistema venoso uterino, entra na circulação e chega ao ovário por via sistêmica (GINTHER et al., 2007). A progesterona atua como promotora da produção de $\mathrm{PGF}_{2 \alpha}$, uma vez que é necessário para a produção de ácido araquidô-

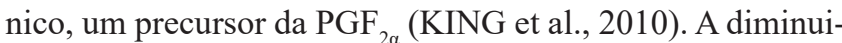
ção da concentração de progesterona no final do diestro, leva ao aumento dos níveis circulantes de FSH e LH necessárias para ovulação do ciclo seguinte (BOTELHO, 2012). O aumento da produção de estradiol pelo folículo dominante, no ciclo consecutivo, permite que a égua volte a entrar em cio 1 a 3 dias após a luteólise (EVANS et al., 1997).

\section{Fotoperíodo}

A sazonalidade reprodutiva da égua tem importantes consequências para a criação comercial equina. Criadores pertencentes às associações de raças que adotam a idade hípica como critério de nivelamento de potros nascidos na mesma temporada procuram acasalar as éguas o mais cedo possível, para obter vantagem de idade sobre os produtos nascidos mais tarde (DAVID, 2010).

O ritmo circadiano fotoperiódico está baseado na organização estrutural do chamado eixo fotoperiódico, um conjunto de elementos neurais e endócrinos interconectados que controlam as respostas fotoperiódicas (DAVID, 2010). Este sistema fotoneuroendócrino (MARONDE; STEHLE, 2007) funciona a partir da captação da informação luminosa na retina e conduzida pelo nervo óptico ao núcleo hipotalâmico supraquiasmático. Por sua vez, este controla a secreção noturna de melatonina, um neuro-hormônio que é produzido e secretado durante a noite pela glândula pineal. Este sinal, através de efeitos na função neuroendócrina, controla as respostas fotoperiódicas sazonais. Porém, o sítio exato de ação da melatonina ainda não foi estudado em equinos. Apesar do papel da melatonina na sazonalidade reprodutiva não ser totalmente conhecido, é aceito que durante as horas escuras, a secreção de melatonina é estimulada pela norepinefrina secretada pelos neurônios sinápticos pós-ganglionares do gânglio cervical superior, onde segundo Sharp et al. (1980), em equinos, isto foi confirmado por meio aplicação de um agonista alfa-adrenérgico, que estimulou a secreção de melatonina.

Bisol (2007) estudou 16 éguas da raça Brasileiras de Hipismo e mestiças, no município de São Borja-RS, divididas em dois grupos, sendo um grupo em fotoperíodo artificial e um grupo controle. Durante o período de transição no outo- no, todas entraram em anestro, não sendo observada diferença em relação ao número de dias entre o início do tratamento com fotoperíodo artificial e a última ovulação e os inícios do tratamento com fotoperíodo artificial e do anestro, bem como entre o número de dias de duração do último corpo lúteo. Entretanto, observou-se diferença no grupo luz em que $75 \%$ das éguas apresentaram diestro prolongado enquanto que no grupo controle isto ocorreu em $40 \%$ das éguas. $\mathrm{O}$ anestro inicia por persistência lútea seguida de inatividade folicular ou por inatividade folicular após um diestro regular. O fotoperíodo artificial iniciado a partir da segunda metade do verão não impediu o início do anestro; entretanto, a maioria das éguas submetidas ao fotoperíodo artificial iniciou o anestro após uma persistência lútea. Conclui-se neste trabalho que o anestro inicia por persistência lútea seguida de inatividade folicular ou por inatividade folicular após um diestro regular. O fotoperíodo artificial iniciado a partir da segunda metade do verão não impediu o início do anestro vernal. A maioria das éguas submetidas ao fotoperíodo artificial iniciou o anestro após uma persistência lútea.

Os estudos sobre a sazonalidade reprodutiva equina têm sido desenvolvidos, em sua grande maioria, com dados obtidos a partir de zonas temperadas que começam nas latitudes $23^{\circ} \mathrm{N}$ e $23^{\circ} \mathrm{S}$, aproximadamente, onde a diferença no comprimento entre o maior e menor dia é cerca de duas horas (GINTHER et al., 2006) Cerca de 20\% das éguas apresentam um período anovulatório de inverno, mesmo em latitudes tão altas quanto $61^{\circ} \mathrm{N}$ (BISOL, 2007).

Um estudo feito no México (BOETA et al., 2006) mostrou que $38 \%$ das éguas apresentaram anestro verdadeiro durante os meses de inverno na latitude $19^{\circ} \mathrm{N}$, e que a duração deste período anovulatório variou dramaticamente entre os indivíduos - de setenta a cento e noventa e seis dias; e, mesmo nestas éguas, houve exibição de comportamento estral (não acompanhado de ovulação) durante o mesmo período. Mesmo em latitudes tão baixas quanto $15^{\circ} \mathrm{N}-22^{\circ} \mathrm{N}$ parece haver redução na atividade ovariana durante os meses de inverno. Neste trabalho, os pesquisadores encontraram atividade ovariana (corpos lúteos e grandes folículos), entre novembro e fevereiro, menor do que entre março e outubro.

\section{Monitoramento do ciclo estral}

\section{Citologia vaginal}

A citologia esfoliativa é um diagnóstico simples, rápido e eficaz, observando-se variações dos tipos celulares vaginais, coincidente com a fase hormonal correspondente, sofrendo modificações ao longo do ciclo estral, sob influência dos hormônios esteroides estradiol $\left(\mathrm{E}_{2}\right)$ e progesterona $\left(\mathrm{P}_{4}\right)$. O epitélio vaginal é responsivo as mudanças do estrógeno circulante e a citologia vaginal pode ser interpretada como uma mensuração indireta das concentrações de estrógeno. A partir do aumento da concentração do estrógeno, as células aumentam e o núcleo diminui, podendo algumas vezes desaparecer (IZAEL, 2007).

As avaliações diárias ou em dias alternados da mucosa vaginal são importantes para o manejo de fêmeas, pois possibilitam a definição do momento apropriado para o acasalamento, facilitando o manejo reprodutivo.

As mudanças das células esfoliativas da vagina são 
observadas em esfregaços simples e rápidos, que permitem estimar a progressão e o desenvolvimento folicular e secreção de estrógenos durante o proestro e estimar dessa forma o início e o final do período fértil (LAGE, 2007).

A parede da vagina não possui glândulas e consiste em três camadas: mucosa, muscular e adventícia. $\mathrm{O}$ epitélio da mucosa é formado por tecido pavimentoso estratificado, e suas células podem conter pequena quantidade de queratoialina, porém não ocorre queratinização intensa com transformação das células em placas de queratina. Sob estímulo do estrógeno, o epitélio vaginal sintetiza e acumula grande quantidade de glicogênio, que é depositado no lúmen da vagina quando as células do epitélio vaginal descamam. A lâmina própria da mucosa vaginal é formada por tecido conjuntivo frouxo rico em fibras elásticas. A camada muscular é formada por conjuntos longitudinais de fibras musculares lisas. Na parte mais interna, próxima à mucosa, esses conjuntos são circulares. Externamente à camada muscular, uma camada de tecido conjuntivo denso, a adventícia, composta por fibras grossas e elásticas, une a vagina aos tecidos circunvizinhos (JUNQUEIRA, 2004). Em razão de ser alvo dos hormônios ovarianos, o epitélio vaginal modifica-se de duas a quatro multicamadas de espessura durante o estro, resultando na esfoliação de células do epitélio superficial. As células são obtidas por meio da passagem de um swab na região caudal da vagina. Conforme o espessamento ocorre, as células vaginais progridem de não queratinizadas para queratinizadas (PORTO, 2007).

A colpocitologia permite determinar de forma indireta, a função folicular ovariana e a presença de cistos foliculares, tumores ovarianos e outros distúrbios hormonais, através do predomínio de células superficiais queratinizadas, fornecendo, uma ideia do nível estrogênico e a confirmação do período fértil (LAGE, 2007).

Alguns cuidados básicos devem ser tomados para a obtenção de esfregaços de boa qualidade, como evitar a presença de sangue em excesso e verificar se a quantidade de material não tornou o esfregaço espesso demais. Há uma grande variação de critérios para avaliação citológica, mas de forma genérica, pode-se definir um bom esfregaço como aquele que possui espessura delgada, arquitetura celular preservada, penetração do corante e distribuição uniforme do material na lâmina. A sequência de exame da lâmina inicia pelo menor aumento, em que devem ser observadas: celularidade, ou seja, o aspecto quantitativo; composição celular, ou seja, o aspecto qualitativo (morfologia individual, arranjo e composição de fundo) (LAGE, 2007).

\section{Classificação das células vaginais}

O epitélio vaginal apresenta células basais, parabasais, intermediárias, superficiais nucleadas e anucleadas. Através do esfregaço vaginal, modificações celulares variadas podem ser usadas para detecção das diferentes fases, durante o ciclo reprodutivo da fêmea (JUNQUEIRA et al., 2004). Lage (2007), estudando o perfil citológico durante 60 dias de éguas da raça Quarto de Milha criadas no nordeste brasileiro, não observou diferenças dentro do mesmo tipo celular de qualquer uma das células do epitélio vaginal, no decorrer dos dias do experimento, havendo constância das células, não indicando assim, substituição de uma célula por outra.

As células basais localizam-se na membrana basal e originam outros tipos de células epiteliais observados no esfregaço vaginal, apresentam núcleos arredondados e quantidade escassa de citoplasma basofílico (LAGE, 2007). Izael (2007), analisando citologia vaginal de jumentas durante 28 dias, observou ausência de células basais nos esfregaços vaginais no decorrer de todo o experimento, isso ocorre devido essas células só sofrerem descamação no momento do parto, não sendo observadas durante o ciclo de jumentas.

As células parabasais, são as menores dentre as células vaginais, são redondas ou ligeiramente ovais, com 15 a $25 \mu \mathrm{m}$, apresentam núcleo central vesicular e com pouca quantidade de citoplasma (LAGE, 2007), concordando com o observado por Izael (2007), que avaliou o perfil citológico vaginal em jumentas, onde as células parabasais possuem as mesmas características acima citadas.

As células intermediárias variam em tamanho podendo ser classificadas em células intermediárias pequenas e grandes. Apresentam bordos irregulares e núcleos menores que as das parabasais (LAGE, 2007).

Células superficiais queratinizadas são células grandes e irregulares. São grandes com bordas anguladas e achatadas, também já foram chamadas de células queratinizadas ou cornificadas (IZAEL, 2007).

\section{Ultrassonografia}

Dentre as técnicas de estudo em reprodução animal, a ultrassonografia em tempo real (USTR) tem se revelado uma técnica precisa, segura e de alta praticidade. É uma técnica de exame de estruturas em que a identificação fisiológica dos tecidos, assim como o diagnóstico de condições patológicas, é realizada de forma dinâmica por meio da reconstituição da anatomia seccional dos órgãos estudados em diversas espécies (GOMES, 2003).

O exame ultrassonográfico em tempo real, associado a gravações em vídeo, tem sido uma ferramenta complementar para o estudo da dinâmica de estruturas reprodutivas em diversos mamíferos, assim como para estudos de eventos reprodutivos discretos, que demandam acompanhamento sequenciado, como é o caso da dinâmica folicular ovariana. Desse modo, a ultrassonografia em tempo real tem permitido, de forma não invasiva, o estudo da dinâmica folicular e do momento da ovulação (MAIA, 2011). O exame transretal proporciona imagens detalhadas das estruturas avaliadas, principalmente devido a proximidade entre o trato reprodutivo e a parede retal.

Gastal (1998) estudou diâmetro dos folículos, presença de corpo lúteo e cistos foliculares, em éguas pôneis criadas em Madison nos Estados Unidos, mediante técnica de ultrassonografia transretal, durante quatro meses. Os resultados mostraram que todos os folículos cresceram a uma taxa semelhante até o dia de desvio, quando o folículo dominante continuava a crescer, chegando aos $23 \mathrm{~mm}$ em média e os folículos subordinados começaram a regredir.

O acompanhamento da dinâmica folicular por meio de imagens ultrassonográficas possibilita o esclarecimento do padrão de crescimento dos folículos ovarianos. O corpo lúteo funcional pode ser detectado pela USTR, no terceiro dia após a ovulação, sendo inicialmente menos ecóico que na 
fase funcional, na qual se apresenta como estrutura ecóica, com limites demarcados, podendo apresentar uma cavidade central anecóica. O fenômeno da luteólise pode ser determinado no momento em que ocorre a redução do diâmetro do folículo (MAIA, 2011).

\section{Dosagem hormonal}

As dosagens de estradiol e progesterona são utilizadas em pesquisa, serviços de fertilização assistida e na monitorização folicular, utilizando-se o plasma do animal (FERRAZ, 2001). Além disso, a análise dos metabólitos da progesterona e estrógeno fecal também tem sido utilizada com sucesso para a monitorização do ciclo estral, gravidez, aborto, puberdade e sazonalidade de várias espécies, todavia, vários estudos, comparando o plasma e valores de esteróides fecais durante o ciclo estral, vêm indicando atraso nas concentrações desses hormônios nas fezes em comparação com as do plasma. Esse tempo de atraso é entre 12hs a dois dias em éguas (SCHWARZENBERGER et al., 1996)

Esses hormônios são dosados em diversas espécies, tais como em fêmeas de Tayassu tajacu, através de kits comerciais, com 12 tiras de microtitulação (MIC), com oito furos cobertos com anticorpo antiestradiol. Os procedimentos são realizados pela medição da absorbância a $450 \mathrm{~nm}$ até 30 minutos após o término da reação, utilizando como referência de comprimento de onda 630-690 nm. As reações cruzadas do estrógeno são identificadas com estrona e estriol - 0,2\%; cortisol, testosterona e progesterona - $0,01 \%$, e a sensibilidade analítica é determinada para cerca de 3-6 pg/mL de estradiol. Já as reações cruzadas de progesterona são identificadas a razão de 3,5\% para $17 \mathrm{a}-\mathrm{OH}$-progesterona, corticosterona, 11-11- desoxicorticosterona, desoxicortisol e pregnenolona e $<0,1 \%$ para $17 \beta$-estradiol, testosterona, estriol, DHEA-S, cortisol e cortisona, e a sensibilidade analítica é determinada para cerca de 0,03-0,07 $\mathrm{ng} / \mathrm{ml}$ de progesterona (MAIA, 2011).

O fator mais determinante no comportamento hormonal do estro na égua parece ser a ausência de progesterona plasmática, e para tanto, esta deve estar abaixo de $1 \mathrm{ng} /$ mL (BOTELHO, 2012). Após 24 a 48 horas da ovulação, as concentrações de progesterona aumentam rapidamente para valores máximos em seis dias (6 a $10 \mathrm{ng} / \mathrm{ml})$, permanecendo altas durante o diestro (STAEMPFLI et al., 2011), e então regridem rapidamente até atingirem os valores baixos, correspondente ao período de estro (MELO, 2012).

Poucas pesquisas têm sido feitas sobre os padrões hormonais durante anestro em equinos, pois se entende que as alterações em padrões hormonais necessários para a transição para o período estral são em resposta a dias mais longos, devido ao fotoperíodo (SLUSHER, 2004).

\section{Considerações finais}

A utilização de técnicas que colaboram com o monitoramento do ciclo estral é importante na reprodução equina, já que as mesmas auxiliam na obtenção de fases do ciclo estral e de doenças reprodutivas.

Com isso, a citologia vaginal que já é considerada uma técnica pioneira na observação do ciclo estral em diversas espécies, juntamente com a ultrassonografia para a ava- liação da dinâmica folicular e as dosagens hormonais tanto por meio do plasma como fecal, vem ganhando mercado na reprodução, todavia, o mesmo ainda é escasso de informações sobre controle estral na espécie equina, devendo ser alvo de constantes estudos e pesquisas para melhor aprimoramento dessas técnicas.

\section{Referências}

BENETTI, A. H. et al. Concentrações séricas de progesterona, 17 ß-estradiol e cortisol durante o final do próestro, estro e diestro gestacional em cadelas. Ciência Rural, v. 34, n. 2, p. 471-478, 2004.

BISOL, J. F. W. Fotoperíodo artificial sobre a atividade reprodutiva de éguas durante a transição outonal. 2007. 40 f. Dissertação (Mestrado em Ciências Veterinárias) Faculdade de Veterinária) - Universidade Federal do Rio Grande Do Sul, Porto Alegre, 2007.

BOETA, M. et al. Ovarian activity of the mare during winter and spring at a latitude of $19^{\circ} 21^{\prime} \mathrm{N}$. Journal of Equine Veterinary Science, v. 26, p. 55-58, 2006.

BOTELHO, J. H. V. Indução hormonal de estro regular em éguas Mangalarga Marchador em transição primaveril. 2012. 41f. Dissertação (Mestrado em Ciências Veterinárias) - Universidade Federal de Lavras, Lavras, 2012.

BRADSHAW, W. E.; HOLZAPFEL, C. M. Evolution of animal photoperiodism. Annual review of ecology, evolution and systematics, v. 38, p. 1-25, 2007.

DAVID, F. F. A. Fotoperíodo artificial no verão pode evitar anestro estacional na égua? 2010. 40 f. Dissertação (Mestrado em Ciências Veterinárias) - Faculdade de Veterinária, Universidade Federal do Rio Grande Do Sul, Porto Alegre, 2010.

DONADEU, F. X.; PEDERSEN, H. G. Follicle development in mares. Reproduction in Domestic Animals, v. 43, p. 224-231, 2008.

DONADEU, F. X.; WATSON, E. D. Seasonal changes in ovarian activity: Lessons learnt from the horse. Animal Reproduction Science, v.100, p.225-242, 2007.

EVANS, T. J. et al. Clinical reproductive anatomy and physiology of the mare. In: YOUNGQUIST, R.; THRELFALL, W. Current therapy in large animal theriogenology. Philadelphia: WB Saunders, p. 46-47, 1997.

FERREIRA, A. I. T. Reprodução equina. 2009. 54 f. Dissertação (Mestrado em Ciência Animal) - Universidade do Porto, Porto, 2009.

FERRAZ, L. E. S. et al. Concentração de progesterona e de estradiol 17-beta e características ultra-sonográficas da vesícula embrionária no início da gestação em éguas Puro Sangue Inglês. Arquivo Brasileiro de Medicina 
Veterinária e Zootecnia, v. 53, n. 4, p.1-7, 2001.

GASTAL, E. L. et al. Echotextural changes in the follicular wall during follicle deviation in mares. Theriogenology, v. 52, p. 803-814, 1998.

GINTHER, O. J. et al. Conversion of a viable preovulatory follicle into a hemorrhagic anovulatory follicle in mares. Animal Reproduction, v. 3, p. 29-40, 2006.

GINTHER, O. J. et al. Luteal blood flow and progesterone production in mares. Animal Reproduction Science, v. 99, p. 213-220, 2007.

GINTHER, O. J. et al. Characterisation of pulses of 13,14dihydro-15-keto-PGF2alpha (PGFM) and relationships between PGFM pulses and luteal blood flow before, during, and after luteolysis in mares. Reproduction, Fertilility and Development, v. 20, p. 684-693, 2008.

GOMES, L. G. Dinâmica folicular ovariana em potras durante as fases pré-púbere e púbere. 2003. 90 f. Dissertação (Mestrado em Medicina Veterinária) Universidade Federal de Viçosa, Viçosa, 2003.

GOUDET, G. et al. Intrafollicular content of luteinizing hormone receptor, a-inhibin, and aromatase in relation to follicular growth, estrous cycle stage, and oocyte competence for in vitro Maturation in the Mare. Biology of Reproduction, v. 60, p.1120-1127, 1999.

GUIMARÃES, D. A. A. et al. Características reprodutivas da paca fêmea (Agouti paca) criada em cativeiro. Acta amazônica, v. 38, p. 531-538, 2008.

HAFEZ, E. S. E.; HAFEZ, B. Reprodução animal. Barueri: Manole, 2004. 509 p.

IZAEL, M. A. Descrição do perfil citológico vaginal de jumentas (Equus asinus) cíclicas e gestantes. 2007. 31 f. Monografia (Graduação em Medicina Veterinária) Universidade Federal Rural do Semi-árido, Mossoró, 2007.

JUNQUEIRA, L. C.; CARNEIRO, J. Histologia básica. Rio de Janeiro: Guanabara Koogan, 2004. v. 10.

KING, S. S. et al. Differential luteolitic function between the physiological breeding season, autumn transition and persistent winter cyclicity in the mare. Animal Reproduction Science, v. 117, p. 232-240, 2010.

LAGE, R. A. Perfil citológico vaginal de éguas da raça quarto de milha criadas no semi-árido nordestino do Brasil. 2007. 39 f. Monografia (Graduação em Medicina Veterinária) - Universidade Federal Rural do Semiárido, Mossoró, 2007.

MAIA, K. M. Fisiologia e controle do ciclo estral em fêmeas de cateto (Tayassu tajacu, Linnaeus, mantidas em cativeiro no semi-árido brasileiro. Mossoró, 2011. 59 f. Dissertação (Mestrado em Ciência Animal) Universidade Federal Rural do Semi-árido, Mossoró.
MARONDE, E.; STEHLE, J. H. The mammalian pineal gland: known facts, unknown facets. Trends in Endocrinology and Metabolism, v. 18, n. 4, p.142-149, 2007.

MELO, C. M. et al. Efficiency of the deslorelin acetate and equine pituitary extract on induction of ovulation in mares. Veterinária e Zootecnia, v.19, n. 03, p. 392-39, 2012.

PEIXOTO, G. C. X.; SILVA, A. R. Diagnóstico de gestação e sexagem fetal em caprinos por ultrassonografia. Acta Veterinaria Brasilica, v. 4, supl. p. 30-35, 2010.

PORTO, R. R. M. et al. Perfil citológico vaginal de ovelhas da raça Santa Inés no acompanhamento do ciclo estral. Ciência Animal Brasileira, v. 8, n. 3, p. 521-528, 2007.

RIBEIRO, V. M. F. et al. Quadro citológico vaginal, concentração plasmática de progesterona durante a gestação e medidas fetais em paca (Cuniculus paca Linnaeus, 1766). Acta Amazônica, v. 42, n. 3, p. 445-454, 2012.

ROMANO, M. A. et al. Biologia reprodutiva de éguas: estudo do ciclo estral e momento de ovulação. Brazilian Journal of Veterinary Research and Animal Science, v. 35, n. 1, p. 25-28, 1998.

SAMPER, J. C. Artificial insemination with fresh and cooled semen. In: SAMPER, J. C. Equine Breeding Management and Artificial Insemination. 2. ed. Estados Unidos: Elsevier Health Sciences, p. 165-174, 2008.

SCHWARZENBERGER, F. et al. Faecal steroid analysis for non-invasive monitoring of reproductive status in farm, wild and zoo animals. Animal Reproduction Science, v. 42, n. 1, p. 515-526, 1996.

SHARP, D. C. Environmental influences on reproduction in horses. Veterinary Clinics of North America: Food Animal Practice, v. 2, n. 2, p. 207-233, 1980.

SLUSHER, S. H. et al. Reproductive management of the mare. Division of Agricultural Sciences and Natural Resources, Oklahoma State University, 2004.

SNOECK, P. P. N. et al. Vaginal cytology of maned sloth (Bradypus torquatus). Pesquisa Veterinária Brasileira, v. 31, n. 3, p. 271-275, 2011.

STAEMPFLI, S. A. et al. Effect of a single injection of long-acting progesterone on the first ovulation in early and late spring transitional mares. Journal of Equine Veterinary Science, v. 31, n. 12, p. 744-748, 2011.

TAROUCO, K. A. Fisiologia reprodutiva da égua. Estacionalidade Reprodutiva: A estacionalidade dos acasalamentos, na maioria das espécies. Disponível em: https://xa.yimg.com/kq/.../ FISIOLOGIAREPRODUTIVADAEGUA.doc. Acesso em: $22 / 09 / 2013$

Recebido em: 23/10/2013 Aceito em: 07/06/2014f 